\title{
POWER GENERATION USING MAGLEV WINDMILL
}

\author{
Harshal Vaidya ${ }^{1}$, Pooja Chandodkar ${ }^{2}$, Bobby Khobragade ${ }^{3}$, R.K. Kharat ${ }^{4}$ \\ ${ }^{1}$ Student, Department of EEE, Marathwada Institute of Technology, Maharashtra, India \\ ${ }^{2}$ Student, Department of EEE, Marathwada Institute of Technology, Maharashtra, India \\ ${ }^{3}$ Student, Department of EEE, Marathwada Institute of Technology, Maharashtra, India \\ ${ }^{4}$ Assistant Professor, Department of EEE, Marathwada Institute of Technology, Maharashtra, India
}

\begin{abstract}
The paper project describes the implementation of different type of a wind turbine for purpose of power generation. A vertical axis wind turbine (VAWT) with use of magnetic levitation technology for optimal performance of wind turbine has been discussed. With the merits of conventional VAWT, the merits of starting at low wind-speed, higher efficiency, low noise emission, etc. are also discussed. The major consequence in front of conventional wind turbine is loss of energy during rotation. By using nature of permanent magnet as a perfect replacement for ball bearings levitation of the turbine is intended thus reducing energy losses while rotation. Using this effect wind turbine blades are placed on a rod for obtaining stability during rotation. Power is then generated by using an axial flux generator, which has incorporated the utilization of permanent magnets and a set of coils.
\end{abstract}

Keywords: VAWT, Magnet, Magnetic Levitation, Wind Turbine, Energy, Wind Power

\section{INTRODUCTION}

An important factor in development of human resource is the Energy. As conventional energy sources are exhausting rigorously, the development of inexhaustible and renewable energy resources, like wind, solar is essential for human life. The wind power been utilized by human being for a greater time period and the technology linked with it is more modified compared to other non-polluting energies. Today wind power is attracting the benefits of power sector and their application is entering into quicker development.

The merits for vertical-axis wind turbine (VAWT) can be noted such as requirement of minimum cost, easy installation, easy maintenance, and the capability to accept wind from all directions. Compared with the traditional horizontal axis wind turbine, this type is levitated or suspended with the help of magnetic levitation directing vertical on a rotor shaft. This technology is utilized as an efficient replacement for ball bearings having its application on the traditional wind turbine. This technology is usually implemented with permanent magnets and is used in between the rotating shaft of turbine blades and base of wind turbine system. The entire rotor weight of wind turbine is balanced by magnetic bearings. The friction of the bearings is eliminated and hence need for bearing lubrication is also eliminated with decrease in the maintenance cost.

Further, this magnetic suspension eliminates mechanical vibration reducing noise. As low friction reduces starting torque of turbine, the magnetic bearings facilitates by producing power at lower wind speed as compared with use of conventional bearings.

Normal VAWT requires very different adjusting mechanism for blades making its structure complicated, costly in fabrication and wastage of power. But comparing with traditional VAWT the blades of magnetic VAWT are constructed for automatic pitch adjustment and hence requirement of any equipment is eliminated. The adjustment of blade pitch is performed naturally during rotation for the necessary angle of attack. This results in production of maximum thrust of wind force improving the efficiency.

\section{LITERATURE REVIEW}

\subsection{Wind Power}

Wind is considered as another form of solar energy because of its origination from difference in heating of atmosphere by sun. The winds relevant to applications of wind turbines are local winds and planetary winds. The second one is most available. Hence it constitutes as important consideration in locating the sites for proper working of wind turbines. The locations of these winds are generally along sea shore, mountain, valleys and open plains.

The wind force may be very strong. During the ancient period, human harnessed this force for important usage like the propulsion of ships using sails before the invention of the engines, in windmills for grinding grain or pumping water for cause of irrigation. At the beginning of the twentieth century concept of electricity found its use and windmills got converted into wind turbines with the rotor coupled to an electric generator. Electricity generated from the wind does not produce Carbon Dioxide emissions and therefore does not contribute to the greenhouse effect.

\subsection{Types of Turbines}

Wind Turbines are divided into two classes: horizontal axis wind turbines (HAWTs) and vertical axis wind turbines (VAWTs). 


\subsubsection{Horizontal Axis Wind Turbines}

Horizontal axis wind turbine can be visualized as conventional box fan, a set of blades connected to a shaft that is parallel to the ground; however, function of turbine is the opposite of a box fan. It normally consists of two to three blades connected to a shaft that is connected to a generator which will produce energy from shaft work. There are two main types of HAWTs, ones that face into wind and ones that face away from wind. Turbines that face into wind require a rudder or some other type of mechanism to be able to self-orientate to face incoming wind. Those that face away from the wind do not need this rudder to self-orientate, however they suffer from a vibration due to support tower blocking part of wind flow.

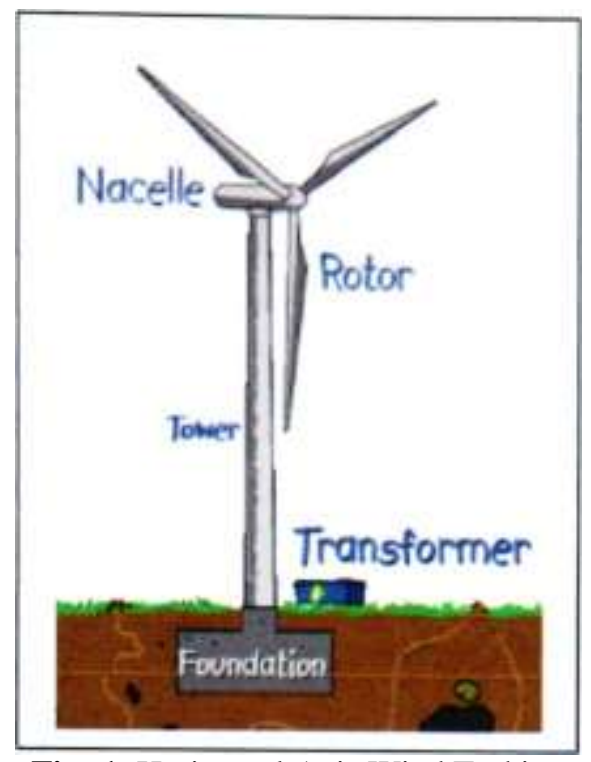

Fig -1: Horizontal Axis Wind Turbine

\subsubsection{Vertical Axis Wind Turbines}

Vertical axis wind turbines operate on same principle of converting rotational movement due to wind into shaft work, which is then converted into electricity through the use of a generator. VAWTs contain a shaft that is perpendicular to ground. Unlike the HAWTs, the VAWTs can catch the wind regardless of the position that they are facing, which can lead to them being more versatile. Also, VAWTs are able to function in more irregular wind patterns than HAWTs are able to. There are two primary blade designs that are used for VAWTs that operate on different principles: the Savonius type and the Darrieus type.

\section{i. Savonius Turbine Type}

Finnish engineer Sigurd Savonius invented the Savonius model. Savonius type blade design uses aerodynamic drag from wind to rotate the blades and produce power. Savonius type blades are rugged and simplistic. This can reduce costs since they are easier to manufacture, need less maintenance, and can last longer in harsher environments. However, they are roughly half as efficient as other lift type such as the Darrieus designs.

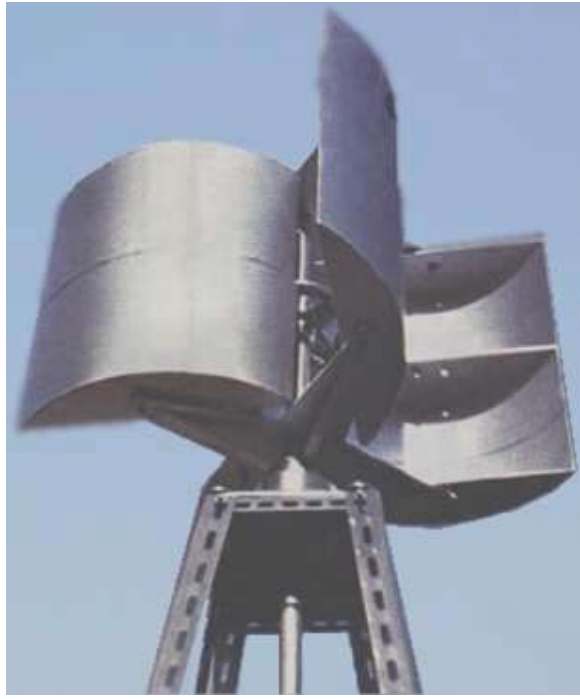

Fig -2: Savonius Vertical Axis Wind Turbine

\section{ii. Darrieus Turbine Type}

French aeronautical engineer, Georges Darrieus invented this turbine. Darrieus type blades use lift forces from wind to rotate the blades. The blades have an airfoil shape, and instead of being oriented horizontally as they would be on an airplane, they are oriented vertically. The air that travels along the outside of the curve must travel at a greater speed than the air on the inside of the blade. This creates an area of lower pressure on the outside of the blade, and therefore a net force on the blade to the outside. By controlling the angle of the blade, this net force causes the blade to rotate.

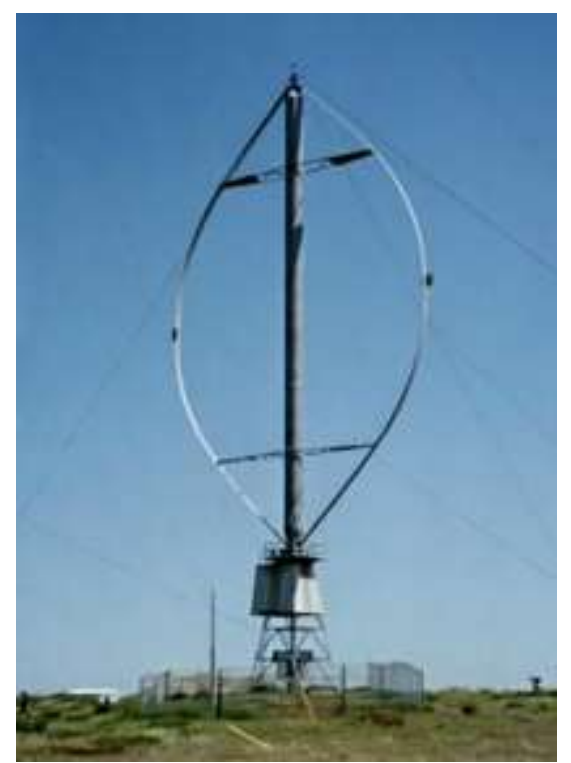

Fig -3: Darrieus Vertical Axis Wind Turbine

There are many different variations of the traditional Darrieus type, also referred to as the "egg-beater" type; these variations include the Giromill (or the "H-Type" Darrieus), the Gorlov helical turbine, and the cycloturbine. Due to the blade going into the wind as opposed to with the wind (as it does in the Savonius type blade), it can spin faster than the speed of the wind, which results in a higher efficiency. However, this higher efficiency comes with a 
great cost. The blade is harder to manufacture than a Savonius blade, increasing the cost of production. Also, normal Darrieus type VAWTs are not self-starting, and thus needs to have a motor or other solution to bring it up to a sufficient speed where it can start producing its own energy.

\section{SYSTEM MODELLING}

\subsection{Wind Power Generation}

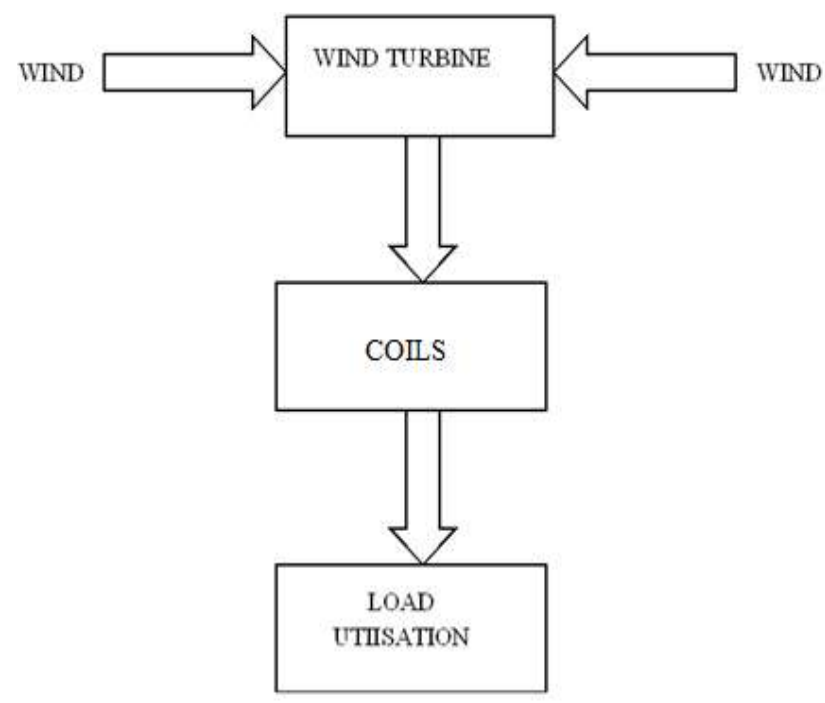

Fig -4: Block Diagram of Wind Power Generation

When the air strike the blade of the turbine, due to the action of repulsive force of the magnet the rotation of the blade increase resulting in rotation of the shaft. Hence induced emf is generated in the generator. Output of turbine is AC power. The bearing arrangement is totally replaced by the neodymium magnet which gives high repulsive force. With the help of this force small amount of air pressure gives maximum rotation which results in large power generation.

\subsection{Power from Wind Turbine}

The power rises as cube of the wind velocity and can be calculated with respect to area in which the wind and wind velocity is available. When wind is in motion the energy produced is kinetic energy. Hence the power from turbine is related to the kinetic energy produced.

Kinetic Energy $=\frac{1}{2} \mathrm{MV}^{2}$

The volume $\mathrm{V}$ ' flowing in unit time through an area A, with wind speed $\mathrm{V}$ is denoted by $\mathrm{AV}$ and mass $\mathrm{M}$ is the product of Volume $V^{\prime}$ and density $\rho$ so: $\quad M=\rho A V$

Putting the $M$ in equation of kinetic energy we get:

Kinetic Energy $=\frac{1}{2}(\rho A V) V^{2}=\frac{1}{2}\left(\rho A V^{3}\right)$

But Power is nothing but the kinetic energy generated by the turbine.

Hence, Power $=\frac{1}{2}(\rho A V) V^{2}=\frac{1}{2}\left(\rho A V^{3}\right)$

Where: Air Density $(\rho)=1.225 \mathrm{~kg} / \mathrm{m}^{3}$

Area $(\mathrm{A})=$ Swept Area of turbine blades

Velocity $(\mathrm{V})=$ wind speed in $\mathrm{m} / \mathrm{s}$

\subsection{Generator}

The generator converts mechanical energy of the shaft into electrical energy output. While designing the axial flux generator observation can be noted that the operating capacity of generator depends on permanent magnet alternators. For these generators air gap is arranged in perpendicular direction to rotating axis and hence produces magnetic fluxes in parallel direction to rotating axis.

\subsection{How Power is Generated}

Wind turbines serve as a means to transform the kinetic energy of wind into power. This process begins when wind contacts the turbine blades and transfers some of its kinetic energy to them, forcing them to rotate. Since the blades are connected to the main shaft through the rotor, the shaft rotates as well, creating mechanical energy. The main shaft is usually connected to a gear box which rotates a parallel shaft at about 30 times the rate of the main shaft. At high enough wind speeds, this amplification creates sufficient rotational speeds for the generator electrical output. Generators generally used in turbines are off-the-shelf and use electromagnetic induction to produce an electrical current. In these generators permanent magnets are arranged surrounding a coil. The shaft connects to the magnet assembly, spinning it around the stationary coil of wire and creating a voltage in the wire. The voltage is what drives the electrical current out of the wire and into power lines to be distributed.

\section{MAGNETIC SUSPENSION (LEVITATION)}

\subsection{Principle}

Magnetic levitation can be explained as technology which suspends or levitates an object with the help of magnetic forces for getting support without any contact and low friction during motion. Due to absence of mechanical contact in the magnetic bearing, advantages of no wear and tear, suitability for long-term use in any environment, absence of mechanical friction, low noise, less amount of power loss and absence of lubrication or sealing can be achieved. Therefore, this technology is beneficial for highspeed applications to satisfy the objective of eliminating mechanical problems power loss.

\subsection{Use of Magnetic Levitation in Wind Turbine}

In recent years, due to rapid growth in the use of material for designing permanent magnet, the magnetic suspension using permanent magnets are approaching towards wind turbine application leading to reduction in the cost as well as stringency of wind power. Due to use of magnetic levitation concept the advantages marked below has obtained:

1. Reduction in starting wind speed

Due to elimination of friction the power output is increased for the same value of wind speed. Hence reduction in starting speed is obtained.

2. Due to utilization of magnetic levitation, design of the conventional wind turbine rotor has largely been affected. 
The use of conventional bearings is based upon careful lubrication for greater service life and higher reliability. With the reduction in operational cost as well as maintenance cost of the bearings reduction in the downtime of turbine is achieved improving the overhaul efficiency.

\section{CONSTRUCTION OF PROTOTYPE}

\subsection{Magnet Selection}

The four configurations in commercial list of magnets are based on formation of their material each configuration of magnet consisting with them its own magnetic properties. Neodymium Iron Boron (Nd-Fe-B) is the new invention in commercialized magnets which constitute highest magnetic properties compared to other magnets at room temperature

From Figure-5 B-H curve depicts attractive magnetic characteristic of Nd-Fe-B offering high flux density with the ability of resisting the property of demagnetization.

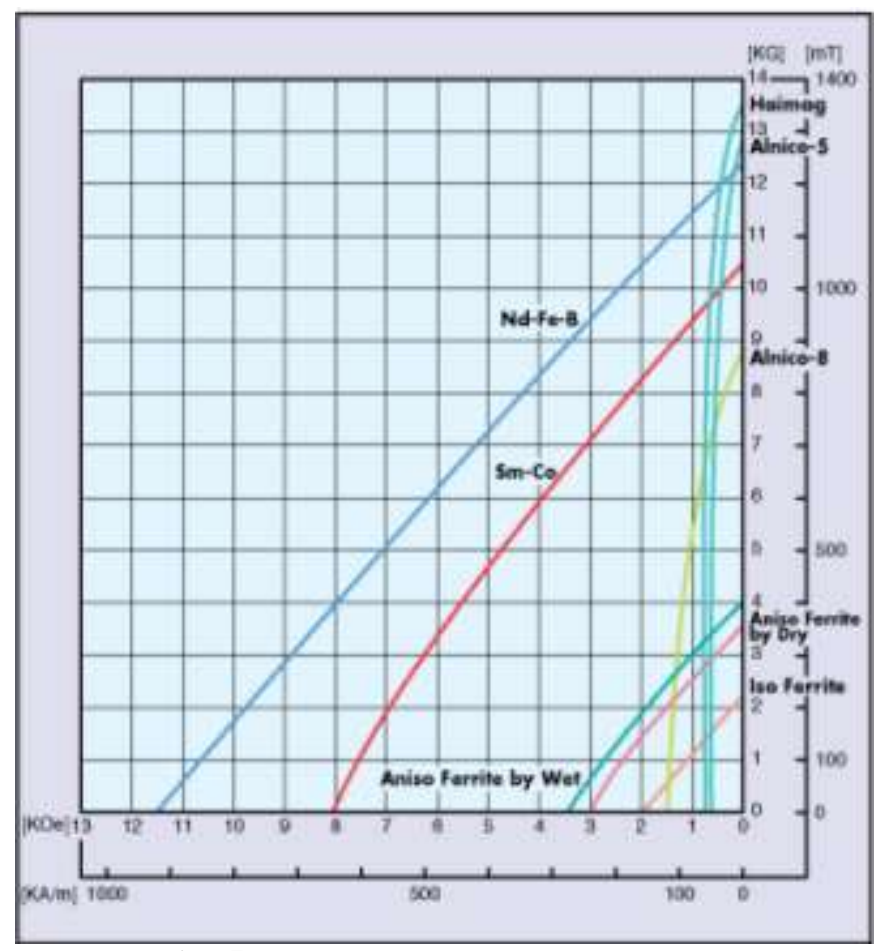

Fig -5: B-H Curve of different Magnets

This configuration becomes most important because of levitation of heavy load and rotation at high speeds exhibiting a high force directing downward on the axis.

If shape of magnets considered where ring or circular, they can be placed on shaft with same poles facing each other enabling repelling force to provide support to weight of turbine which minimizes use of magnets required to fulfill the idea.

The permanent magnets selected were the N42 grade Nd-Fe$\mathrm{B}$ having ring shape which consist of nickel plating for strengthening and protecting the magnet..

\subsection{Magnet Placement}

Two ring shaped neodymium $(\mathrm{NdFeB})$ magnets are arranged at middle of shaft by which necessary suspension between stator and rotor is obtained. Similarly disc magnets having parameters $10 \mathrm{~mm}$ in diameter and $4 \mathrm{~mm}$ height are placed as one North Pole and one South Pole one after the other, along the rotor circumference of $40 \mathrm{~cm}$ diameter. These magnets supply the useful flux which is utilized for the power generation.

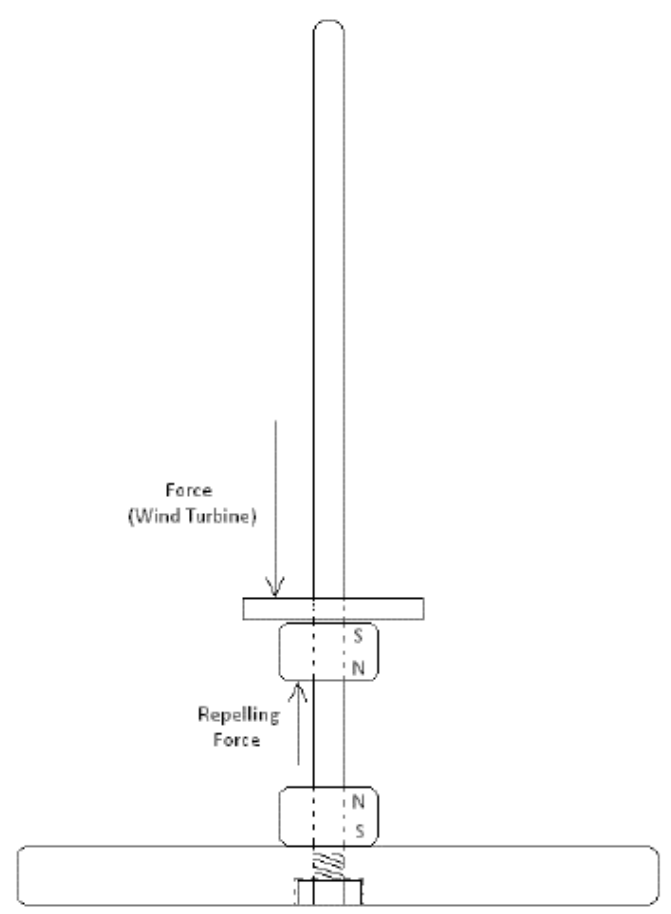

Fig -6: Magnet Placement of NdFeB Magnets

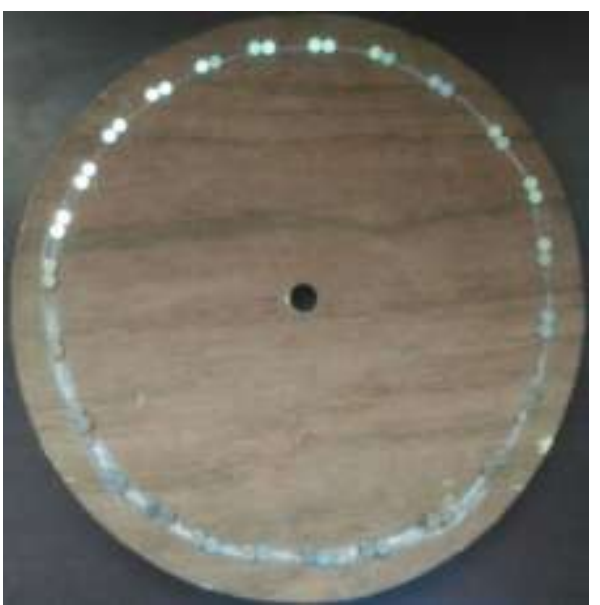

Fig -7: Magnet Placement of Disc Magnets on rotor

\subsection{Coil Design and Arrangement}

To design the definite number of turns per coil is difficult. If the more turns are wound it increase the emf generated from each coil but increase the size of every coil. For minimizing the size, wire having higher gauge can be used. If the diameter of wire is small low amount of current flows leading to heating of wire because of the increased resistance of wire which another difficult task. 
While designing generator for given application, fact must be known that the problem attached with large coil size is the problem field density. The increase in coil height increases gap between two magnets leading to reduction in magnetic flux. Hence necessary voltage and current must be balanced.

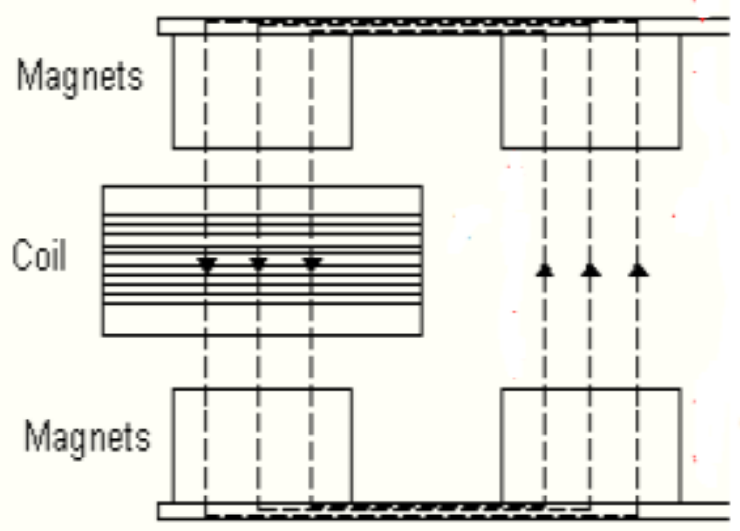

Fig -10: Coil and Design

The Coil placement is organised on the stator circumference exactly under the disc magnets placed on rotor. Each coil is kept in series to get maximum output voltage.

The wire used to design the turns of one coil is of 24 gauge having 100 turns. 15 sets of coils are arranged in series connection in the prototype. The coil arrangement is shown in figure.

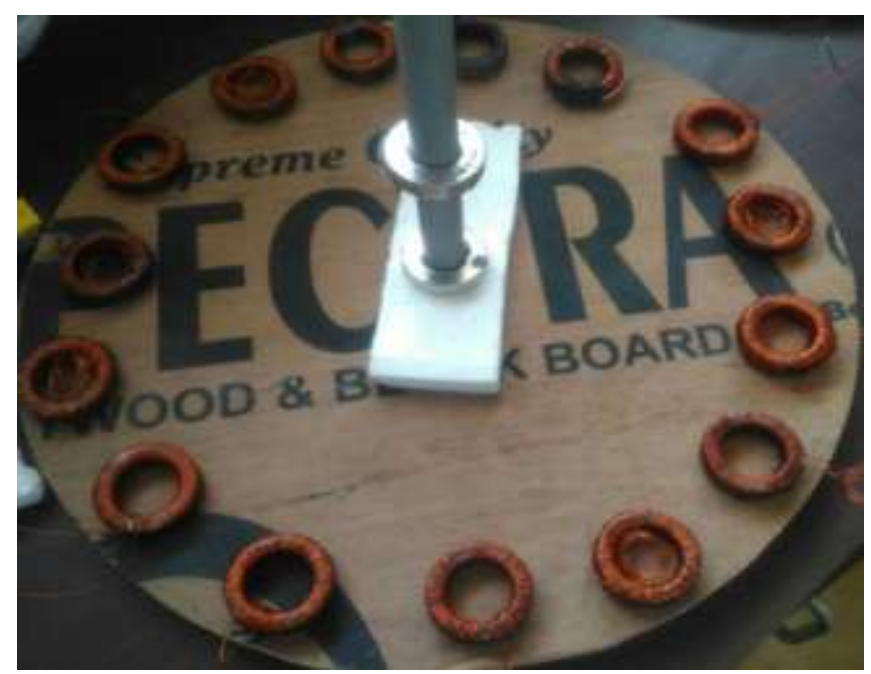

Fig -11: Coil Arrangement

\subsection{Blade Design}

Savonius type blade design is used because they are rugged and simplistic reducing cost. The manufacture is easier, less maintenance, and durable in harsher environments.

This design was obtained from aluminum sheet and due to the flexible nature of the metal sheet, desired shape was obtained. The blade was designed for height of $400 \mathrm{~mm}$.

\section{CONCLUSION}

The concept of vertical axis wind turbine using magnetic levitation successfully worked. Comparing with traditional horizontal wind turbines, single Maglev turbine having large capacity gives more output.

The turbine efficiency is improved by utilization of magnets helping to spin with fast speed with negligible friction as it cancels out the stress on the shaft of the turbine. This modern design of turbine gives more power output with higher efficiency compared to conventional wind turbine. For avoiding the vibration of the rotor, shaft was used..

The standard windmills having set of 1000 windmills powers 5 lakhs homes while single maglev wind turbine is capable supplying power to 7.5 lakhs homes. The required area for single maglev windmill is less than 100 acres while field of 1000 windmills require more than 64,000 acres. From this observation we can say that a single maglev wind turbine is economical compared to Conventional wind turbine

\section{FUTURE SCOPE}

The vertical axis wind turbine with magnetic levitation may be mounted on residences. Here it can be erected on rooftop with very efficient and practical approach. House owner would be capable for extraction of free and clean energy with a minimized utility cost. For medium power generation this design can be used.

Power generated from this turbine can be utilized in remote places where traditional method of supplying power is costlier. Power generated from turbine can be efficiently used for Street/domestic lighting and domestic appliances.

\section{ACKNOWLEDGEMENT}

We are thankful to Dr J. H. Godihal, Principal, Marathwada Institute of Technology, Aurangabad for his encouraging attitude. We are also grateful to the Prof. Mrs. S. M. Badave, H.O.D, Dept. of Electrical and Electronics Engineering for providing a solid background for our studies and research thereafter. We would like to give our gratitude and thanks to Prof. Ms. R. K. Kharat for her precious guidance and encouragement.

We feel pleasure to express our profound gratitude to the teaching and non-teaching staff of Electrical and Electronics Engineering and our friends for their valuable encouragement, timely suggestions and continuous support and providing us with all the necessary information.

Lastly, we feel obliged for blessings of our beloved parents

\section{REFERENCES}

[1] Minu John, Rohit John, Syamily P.S, and Vyshak P.A" Maglev Windmill", International Journal of Research in Engineering and Technology, Volume: 03, Issue: 05, May2014. 
[2] Dinesh N Nagarkar and Dr. Z. J. Khan, "Wind Power Plant Using Magnetic Levitation Wind Turbine", International-Journal of Engineering and Innovative Technology (IJEIT) Volume 3, Issue1, July 2013.

[3] Vishal D Dhareppgoal and Maheshwari M Konagutti, "REGENEDYNE Maglev Wind Power Generation", SARCIRAJ International Conference, Pune, India, 16th June 2013. [4] A. Albani, and M. Z. Ibrahim, "Preliminary Development of Prototype of Savonius Wind Turbine For Application In Low Wind Speed In Kuala Terengganu, Malaysia", International Journal of Scientific \& Technology Research (IJSTR) Volume 2, Issue 3, March 2013.

[5] Tapan H. Barot, Hitesh Jariwala, and Mayur Kevadiya, "A Review on Straight Bladed Vertical Axis H-Type Darrieus Wind Turbine", International Journal of Innovative Research in Science Engineering and Technology Vol. 4, Special Issue 6, May 2015.

[6] Girish M Prajapati, Abrarkhan Pathan, and Mr. B. J Patel, "A Review: Aerodynamic Analysis On Vertical Axis Wind Turbine Blade", International Journal of Advance Engineering and Research Development Volume 1, Issue 12, December -2014.

[7] Piyush Gulve, and Dr. S.B.Barve, "Design And Construction Of Vertical Axis Wind Turbine", International Journal of Mechanical Engineering and Technology (IJMET), Volume 5, Issue 10, pp. 148-155, October 2014.

[8] Prof. S A Mohan Krishna, "An Investigative Study on Design and Thermodynamic Aspects Of A Light Duty Vertical Axis Wind Turbine," International Journal of Innovative Science, Engineering \& Technology, Vol. 1 Issue 8, October 2014.

[9] Yamini Sarathi, Khemraj Patel, Arti Tirkey, Prakash Kumar Sen and Ritesh Sharma, "Study On Wind Turbine And Its Aerodynamic Performance", International Journal of Mechanical Engineering and Robotic Research Vol. 4, No. 1, January 2015.

[10] B. Loganathan, I. Mustary, H. Chowdhury and F. Alam, "Study of a Savonius Type Wind Turbines for its Aerodynamic Characteristics", 19th Australian Fluid Mechanics Conference Melbourne, Australia, 8-11 December 2014.

[11] Ashwin Dhote, and Prof. Vaibhav Bankar, "Design, Analysis and Fabrication of Savonius Vertical Axis Wind Turbine", International Research Journal of Engineering and Technology (IRJET) Volume: 02 Issue: 03, pp. 2048-2054, Jun-2015.

[12]B. Bittumon, Amith Raju, Harish Abraham Mammen, Abhy Thamby and Aby K Abraham, "Design and Analysis of Maglev Vertical Axis wind Turbine", International Journal of Emerging Technology and Advanced Engineering Volume 4, Issue 4, pp. 374-379, April 2014.

[13] Hardik Patel and Sanat Damania, "Performance Prediction of Horizontal Axis Wind Turbine Blade", International Journal of Innovative Research in Science, Engineering and Technology Vol. 2, Issue 5, May 2013

[14] Amit D. Patil, Amit W. Chake, Manoj I. Helonde and Pravin M. Gupta, "Vertical Axis Wind Turbine with Maglev Technology," International Journal for Scientific Research \& Development, Vol. 2, Issue 12, 2015.

[15] Ajay L. Parate, Pawan M. Kumbhare, Rahul C. Patekar, and Pravin Gupta, "Maglev Power Generation- A Review", International Journal for Scientific Research \& Development, Vol. 2, Issue 12, 2015. 